\title{
PERSONALITY CHARACTERISTICS THAT PREDICT EFFECTIVE PERFORMANCE OF SALES PEOPLE
}

\author{
WILLEM VERBEKE \\ School of Economics, Erasmus University \\ (First received January 1992; accepted in revised form February 1993)

\begin{abstract}
In sales literature the role of personality traits in the prediction of salespeople's performance is a hot topic. This study, based upon an administered personality test, suggests that salespeople's personality traits - specifically, the ability to elicit information from others, to self-monitor during conversations, and to adapt during conversations - are good predictors of performance.
\end{abstract}

Key words: Sales management, personality traits, complex systems theory, conversations, recruitment.

\section{INTRODUCTION}

Ever since Churchill et al.'s meta-study (1985) showed that personality traits account for only $4 \%$ of the variance in outcome-based sales performance, studies relating personality and performance have not been popular. Nonetheless, European managers remain greatly interested in these topics, for several reasons. (1) In many European companies, company sales positions serve as the first step in a long-term career ladder, and many managers want to know if prospective employees will be suitable also in this context. (2) Since salespeople are not easily fired in Europe, managers want to know as much as possible before they take anyone on. (3) Given the importance of social skills in sales, managers want to test prospective recruits to identify the team players.

In line with this trend, more and more business schools are preparing personality profiles of students for corporate recruiters (Byrne, 1991); and in a well-known study (which will be examined later), Spiro and Weitz (1990) discovered that some personality traits (such as self-monitoring) correlate well with success in adaptive selling and subsequent performance. In this paper we will examine some earlier research on sales interactions and personality traits, and will present a process formulation of the sales-client interactions inspired by recent developments in complex systems theory. We will then develop a personality profile based upon the process approach to sales-client interactions. Finally, we will discuss empirical tests of those scales and formulate managerial implications.

\section{PERSONALITY TRAITS AND ADAPTIVE SELLING BEHAVIOUR}

Personality traits are what Churchill et al. (1985) call personal "aptitude" characteristics, which they define as psychological characteristics that enhance or constrain a person's ability to 
perform. In principle these aptitude characteristics are relatively stable, particularly relative to skills, knowledge and task proficiency.*

In the Spiro and Weitz study (1990), four important observations are made. (1) Adaptive selling is a five-dimensional construct relating to different sales approaches, namely the ability to recognize the approaches, to alter them, collect information relevant to them, and actually use them. The implication here is that adaptive selling can be learned; thus training is worthwhile. (2) Adaptive behaviour correlates with motivational style (intrinsic motivation), personality characteristics (self-monitoring, empathy, locus of control and androgyny) and self-reported performance. (3) Spiro and Weile's approach to adaptive selling is inspired by "Inethodological individualism", which holds that it is the salesperson who has the knowledge and technique to change the course of the sales conversation. Unfortunately, the client's contribution to the conversation and the resulting dynamics are not accounted for. (4) Performance is not viewed as a multidimensional concept. Rather, the overall performance of the salesperson is scored on a 1-5 scale.

The model of Spiro and Weitz (1990) is summarized in Fig. 1.

\section{A PROCESS FORMULATION OF THE SALES-CLIENT INTERACTION}

Important progress in framing the dynamics of the conversation has been achieved in the literature on "self-organizing systems" or "complex systems" (Maturana and Varela, 1985; Prigogine and Strengers, 1985; Newtson, 1990; Rapp et al., 1990). Within the theoretical framework of complex system theory, a conversation is perceived as a continuous interaction or "loose coupling" between two subsystems which over time contributes to a positive conversational spiral, which in turn results in a "patterned" system or a "higher-order" system (Jantsch, 1980; Shoner and Kelso, 1988).

This higher-order system is self-organizing, which means that the specific content of the conversation and the patterned behaviours which emerge during the conversation result from cognitive and emotional efforts (or inputs) on the part of both seller and client.

These mutual efforts (to be described below) consist of cognitive information and emotional affordance, to which both participants can respond so that a positive spiral within the conversation can emerge (Baron and Bourdreau, 1987). (1) Cognitive information, according to Sperber and Wilson (1987), is a function of the participants' efforts to be relevant during a conversation. The boundaries of the cognitive environment or context are established when both interlocutors agree on the topic of conversation. It is only within this cognitive enviromment that attitudes can be changed, prices negotiated and the results of the conversation evaluated. As Sperber and Wilson $(1987$, p. 700$)$ noted:

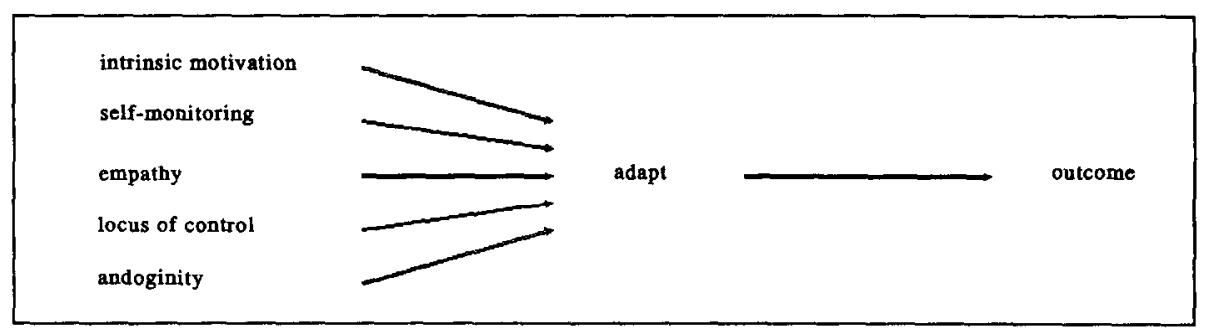

Fig. 1. Spiro and Weitz (1990).

*One must remember that the distinctions made by Churchill et al. are not accepted by everyone. For an overview of different theories on personality, see Pervin (1989). 
A change in the mutual cognitive environment of two people is a change in their possibilities of interaction (and, in particular in their possibilities of further interaction).

(2) Emotional affordance is also essential to the positive spiral since the expression of emotions by one interlocutor invites the other to respond, and vice versa. Studies of depressive people communicating with normal people have shown that depressive people are unable to evoke the positive spiral within a conversation because their communication style is highly self-centred and because too much detailed private information is disclosed. This inability to establish a mutually satisfactory cognitive environment leads to an immediate rejection by the listener, which then evokes anger in the depressive. The anger then further degrades the cognitive environment and emotional affordances, thus generating a negative spiral.

When a positive spiral is achieved, the conversation will eventually reach a stage where "flow" or "behavioural meshing" occur. At that point, the topics of the conversation become more focused, a regular pattern exchange emerges and the behaviours of both participants become synchronized (also called the comfort zone). Two points are essential in this description of the selforganizing conversation: (i) the behaviours of both speaker and listener contribute to the dynamics; and (ii) a high degree of spontaneity eventually develops. This description of the dynamics of a conversation is the basis for the design of the scales used in this paper. Note that the spontaneous hehaviour described ahove (which clients appreciate so much), differs from what Spiro and Weitz call "working smarter", in that "working smarter" stresses continuous cognitive adaption on the part of the salesperson.

\section{THE SFIJECTION AND MEASUIREMENT OF PERSONAI ITY TRAITS}

The selection of the scales used in this paper was arrived at in the course of interviews with experts in personality research. The view of the sales-client interaction described above was mentioned to them, and the characteristics that were perceived by the experts as influencing the salesperson's performance were self-monitoring, interpersonal control, personal efficacy, openers, rigidity and adaptation.

(1) Effective salespeople will score higher on the self-monitoring test, a trait which refers to their tendency to adapt their behaviour to the social situation. People who score high in self-monitoring seem to be able to tailor their personality to any particular situation. For example, if a situation calls for the conformity, the self-monitors conform. They also go out of their way to learn about those with whom they might interact and the rules for appropriate interaction. These techniques allow self-monitors to provide appropriate information to which the listener will respond, thus encouraging a positive spiral in the conversation (Athay and Darley, 1981; Snyder and Gangestad, 1986; Baron and Bourdreau, 1987). Two examples of the scale items are: (i) I find it easy to imitate the behaviours of others; and (ii) during a party, I feel that I should tell jokes to other people.

Hypothesis 1: Effective salespeople will score significantly higher than ineffective in the selfmonitoring test. This test, validated by Snyder and Gangestad (1986), was translated into Dutch.

(2) Effective salespeople will score higher on the interpersonal control test (Paulhus, 1983; Paulhus and Martin, 1988). Interpersonal control, a dimension of the construct called "Locus of Control" (Rotter, 1966), is a measure of people's tendency to control the flow of interpersonal contact. As suggested earlier, it is crucial to create a cognitive environment which encourages a 
positive spiral in the conversation. We believe that people scoring highly on the interpersonal control will possess that ability. Two examples of the scale items are: (i) I have no problems in making friends; and (ii) I find it easy to play a crucial role in group dynamics.

Hypothesis 2: Effective salespeople score significantly higher than ineffective on the interpersonal control test. This test, validated by Paulhus and Martin (1988), was translated into Dutch.

(3) Effective salespeople will score higher on the personal (or self-)efficacy scale, which was originally constructed by Bandura. This personality trait, studied by Paulhus and Martin (1988), implies a positive expectation that what needs to be done can be done. People scoring high in self-efficacy believe they are capable of exhibiting the particular behaviour required by the situation. We believe that people who score on this scale might remain confident and relaxed during a conversation which allows them to contribute positive emotional information, thus encouraging a positive conversational spiral. Two examples of the scale items are: (i) people often succeed because of luck; and (ii) when I want to, I can do almost anything.

Hypothesis 3: Effective salespeople score higher than ineffective on the personal efficiency test. This test, validated by Paulhus and Martin (1988), was translated into Dutch.

(4) Effective salespeople will score higher on the openers test (Miller et al., 1983). During conversation, the salesperson's goal is to gather information about the client so as to respond optimally to his needs. The openers test measures the salesperson's abilities to elicit information from the client and to socialize with people, abilities likely to encourage the positive conversational spiral. Two examples of the scale items are: (i) I am able to keep people talking about themselves; and (ii) I am open to other people.

Hypothesis 4: Effective salespeople will score higher than ineffective on the openers test. This test, validated by Miller et al. (1983), was translated into Dutch.

(5) Effective salespeople will score lower on the rigidity test (Luteijn et al, 1985). The rigidity test measures peoples' openness to new conversations. Since conversations are self-organizing systems in which many directions or dynamics are possible, successful participation requires that the interlocutor be "open" to the situation. Two examples of the scale items are: (i) I manage my work in a flexible way; and (ii) I do what other people expect of me.

Hypothesis 5: Effective salespeople will score lower than ineffective on the rigidity test. This test, originally written in Dutch, was validated by Luteijen et al. (1985).

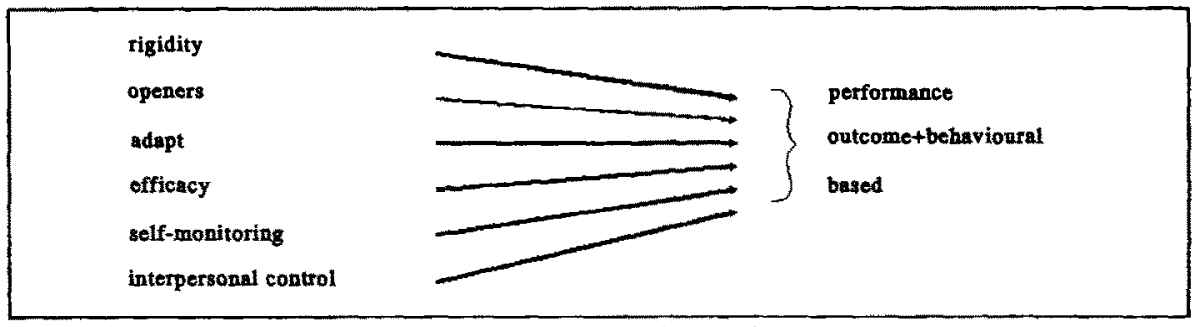

Fig. 2. The model to be tested. 
(6) Effective salespeople will score higher on the adaptation test (Spiro and Weitz, 1990). It is hypothesized that at the beginning of the conversation (when it is not yet patterned) effective adaptive behaviour exhibited by the salesperson will substantially improve the dynamics of the conversation. Remember that, while Spiro and Weitz (1990) see adaptation as a skill, we see it as a personality trait. Two examples of the adaptation scale are: (i) I change my conversational style to fit different situations; and (ii) each client requires a different sales approach.

Hypothesis 6: Effective salespeople will score higher than ineffective on the adaptation test. This scale was validated by Spiro and Weitz (1990) and translated into Dutch. Figure 2 puts our hypotheses in a nutshell.

\section{DESIGN AND DATA COLLECTION}

Managers from 10 different companies were asked to divide their salespeople into two groups: effective and ineffective. They were also asked to define what they meant by an effective salesperson. Judging by their responses Dutch managers evaluate their salespeople on both outcomebased performance ( 1 - sales volume) and behaviour-based performance ( 2 - establishment of new relationships with customers; 3 - maintenance of long-term relationships with customers).

On the basis of these three criteria, salespeople are classified as effective or ineffective. Both effective and ineffective salespeople were selected in the following way. Three-hundred and forty questionnaires were sent to the sales managers of 10 companies in five different industries.* While it is common in the sales literature to study sales people in companies in one industry (e.g. Churchill, 1990), the present study purposely cuts across industries. By not limiting the study to one industry, we selected companies which were all American multinationals with similar training routines.

Company sales managers were asked to mark an " $A$ " for effective salespersons and a " $B$ " for ineffective ones and then to pass on the questionnaires to their salespeople. The salespeople, of course, did not know what the letters represented and thus these markings did not affect the results. Self-addressed envelopes were enclosed so that the salespeople could return the questionnaires directly to us. Twenty-five per cent of the questionnaires were returned. Forty-one salespeople were classified as effective and twenty-nine as ineffective. The reason why more effective salespeople returned their questionnaires could be (i) that the sales managers gave more questionnaires to the better salespeople, (ii) less effective salespeople were not willing to share their information, (iii) ineffective salespeople might have left the company, or (iv) managers probably tend to rate their people as effective - or why would they employ them? However, the real cause was not investigated.

\section{EMPIRICAL RESULTS}

When the data had been collected, scale items which could lower the Cronbach alpha of each scale were deleted. Table 1 shows how many questions were retained and the resulting Cronbach alpha.

*Ten different companies were asked to participate. These companies were drawn from five different industries: computer manufacturers, fast-moving consumer goods manufacturers, publishing companies, copy machine manufacturers, pharmaceutical companies and insurance agencies. All of the companies were subsidiaries of American multinationals. 
Table 1. The results of scale development and ANOVA test

\begin{tabular}{lcccccc}
\hline & $\begin{array}{c}\text { Items } \\
\text { deleted }\end{array}$ & $\begin{array}{c}\text { Items } \\
\text { used }\end{array}$ & Mean & Variance & $f$ & $P$ \\
\hline Self-monitoring $\alpha=0.81$ & 1 & 17 & 3.0 & 0.28 & 11.6 & 0.00 \\
Interpersonal control $\alpha=0.77$ & 3 & 7 & 3.8 & 0.15 & 1.9 & 0.16 \\
Openters $\alpha=0.77$ & 0 & 10 & 3.5 & 0.09 & 7.0 & 0.01 \\
Rigidity $\alpha=0.84$ & 12 & 13 & 2.5 & 0.42 & 0.5 & 0.45 \\
Adaptation $\alpha=0.87$ & 0 & 15 & 3.8 & 0.12 & 5.4 & 0.02 \\
Personal efficacy $\alpha=0.73$ & 7 & 3 & 3.3 & 0.09 & 0.16 & 0.68 \\
\hline
\end{tabular}

Many scales have significant correlations (Tables A1-A3 in Appendix), as was also the case in Spiro and Weitz (1990). A search for correlations between the scales for ineffective salespeople shows them to be low compared to those for effective salespeople. This could mean that sales success has a high correlation with scores on all characteristics except rigidity, which the low scores do not. If it is true that effective salespeople score highly on all the scales (and one strength cannot compensate for one weakness), this might suggest that sales managers will not be able to apply compensatory decisions rules to the selection of salespeople (Patton and King, 1992).

The ANOVA test (Table 1) shows a significant difference between effective and ineffective salespeople on the self-monitoring, openers and adaption scales. However, the other personal characteristics (self-efficacy, interpersonal control and ridigity) did not differentiate between the two groups; this was not hypothesized.

Discriminant analysis was used to determine the accuracy of the scales as a tool for classification. The results of discriminant analysis are given in Table 2.

According to discriminant analysis, $71 \%$ of the sales people could correctly be classified as either effective or ineffective and at face value this is quite satisfactory. However, in order to test for the predictive validity, we must determine whether the discriminant analysis remains stable when the population is split in a training set and test set, each within 11 independent populations (Lachenbruch, 1975). Table 3 shows the results of this test.

When the predictive validity was tested, the discriminant functions drop to $64 \%$ and also shows a high standard deviation (18.5). This lower predictive validity can be explained by the size of the test set. On average, however, the predictive ability of the scales is still satisfactory. From this statistical analysis it can be concluded that effective salespeople differ from ineffective salespeople predominantly in three characteristics: self-monitoring, openers and adaptibility.

Table 2. The results of the discriminant analysis

\begin{tabular}{llll}
\hline Standardized discriminant function coefficients & \multicolumn{2}{l}{ Ranking by correlation with the discriminant variables } \\
\hline SM & 0.79 & SM & 0.88 \\
IC & -0.27 & OP & 0.69 \\
OP & 0.36 & AD & 0.60 \\
RI & 0.30 & IC & 0.40 \\
AD & 0.34 & PE & 0.26 \\
PE & -0.05 & RI & -0.15 \\
\hline
\end{tabular}

The group centroids are: group $1: 0.38 ; 2: 0.56$. The eigenvalue of the discriminant function is: 0.22 with a canonical correlation of 0.42 . The Wilks lambda is 0.81 ; chi-square: 12.76 ; d.f. 6 and sig 0.04 . 
Table 3. The results of the distriminant function using the training and test sets

\begin{tabular}{lcc}
\hline & Training set & Test set \\
\hline 1 & 71.4 & 83.3 \\
2 & 68.2 & 83.3 \\
3 & 74.6 & 50.0 \\
4 & 73.0 & 50.0 \\
5 & 71.4 & 66.7 \\
6 & 73.0 & 83.3 \\
7 & 73.0 & 66.7 \\
8 & 73.0 & 33.3 \\
9 & 68.2 & 83.3 \\
10 & 73.0 & 33.3 \\
11 & 69.8 & 66.7 \\
Mean & 71.7 & 63.6 \\
s.d. & 2.0 & 18.5 \\
\hline
\end{tabular}

\section{DISCUSSION OF THE RESULTS}

During the study it became clear that the personality traits self-monitoring, openers and adaptive ability are the most important characteristics which distinguish effective from non-effective salespeople; and, of these, self-monitoring was the most important. Self-monitoring is a trait which attracted much attention by researchers in connection with many socio-psychological phenomena. For instance, subjects' responses to the self-monitoring scales predict many important social behaviours such as (i) sensitivity to job applicants' credentials (Synder et al., 1988), (ii) dating (Glick, 1985), and (iii) suseptibility to various kinds of advertisements (Synder and DeBono, 1985). The self-monitoring scale has been constructed to reflect five different dimensions: (i) concern for appropriateness of social behaviour, (ii) attention to social comparison information, (iii) ability to control or modify self-presentations, (iv) ability to adapt to various situations, and (v) cross-situational variability of social behaviour (Synder, 1974, p. 529). Given these dimensions of the self-monitoring scale, it is not surprising that there is a high correlation for self-monitoring with both openers and adaptive ability (Tables A1-A3 in Appendix). In other words, self-monitoring "by definition" refers to the ability to elicit information and, more importantly, to the ability to adapt behaviour as required by the social environment. 'This finding, that self-monitors are adaptive, has also been described by Spiro and Weitz (1990). From the data, it might be inferred that sales managers (i) could be trained to look for these personality traits during the recruitment of salespeople, or (ii) could administer the self-monitoring test to their recruits.

In the Introduction, it was suggested according to Churchill et al.'s (1985) meta-study that personal characteristics explain only a small amount of the variance of the salespersons performance. The present study shows that improved design can definitively enhance the discriminatory role of personality tests. Since Churchill's study mainly involved personality tests constructed before 1970 , perhaps it is not surprising that their performance was found inadequate. In the last 20 years, further research on human personality has resulted in many new discoveries. In the U.S.A. the recent trend is to use more personality tests (Kern, 1988).

While the results of this study are not altogether conclusive, they do indicate that further research is needed on personality characteristics and how they can be used to predict sales success. In particular, additional traits might be added to the test and the high correlation between the different scales explored (Lennox, 1988). 


\section{IMPLICATIONS FOR MANAGERS}

(1) Although these scales may serve as a useful aid in the selection of salespeople, managers must remember that for about $29-34 \%$ of the time they could result in incorrect classifications. It is well known, however, that psychological tests are only part of a hiring process that should depend mainly on interviews (Fleenor, 1987). (2) It is possible that what have been called personality traits in this paper are actually skills. If so, managers might encourage salespeople to be more open to clients and to learn new adaptive behaviours.

\section{CONCLUSIONS}

In this paper we have analysed the way in which salespeople manage sales-client conversations. These conversations are perceived as self-organizing systems. It is suggested that better salespeople possess personality traits which enable them to guide the evolution of a conversation. This study provides some indirect evidence that personality traits, and especially the self-monitoring scale, can predict sales success.

\section{REFERENCES}

Athay, M. and Darley, J., Toward an interaction-centered theory of personality. In: N. Cantor and J. Kihlstrom (Eds), Personality, Cognition, and Social Interaction (Hillsdale, NJ: Erlbaum, 1981).

Baron, R, and Bourdreau, L., An ecological perspective on integrating personality and social psychology, Journal of Personality and Social Psychology (1987), pp. 1222-1228.

Byme, J., Wharton school rewrites the book on B-schools, Business Week (1991), May 13, p. 43.

Churchill, G., Ford, N., Hartley, S. and Walker, O., The determinants of salesperson performance: a meta analysis, Journal of Marketing Research (1985), pp. 103-118.

Churchill, G., Ford, N. and Walker, O., Sales Force Management (Homewood, IL: Irwin Press, 1990).

Fleenor, C. P., Assessment center selection of sates representatives, Journal of Personal Selling and Sales Management (1987), pp. 75-79.

Glick, P., Orientation towards relationships: choosing a situation in which to begin a relationship, Journal of Experimental Social Psychology (1985), pp. 544-562.

Jantsche, E., The Self-Organizing Universe (Oxford: Pergamon Press, 1980).

Kern, R., IQ tests for salesmen make a comeback, Sales and Marketing Management (1988), April, pp. 42-46.

Lachenbruch, P., Discriminant Analysis (New York, NY: Hafner Press, 1975).

Lennox, R. D., The problem with self-monitoring: a two sided scale and a one-sided theory, Journal of Personality Assessment (1988), pp. 58-73.

Luteijn, F., Starren, J. and van Dijk, H., Nederlandse Persoonlijkheids Vragenlijst (Leiden, The Netherlands: Swetz and Zeitlinger, 1985).

Maturana, H. and Varela, F., The Tree of Knowledge, The Biological Roots of Iluman Understanding (Boston. MA: Now Science Library, 1985).

Miller, L., Berg. J. and Archer, R., Openers: individuals who elicit intimate self-disclosure, Joumal of Personality and Social Psychology (1983), pp. 1234-1244.

Newtson, D., Alternative representations: comments on the ecological approach, Journal of Contemporary Social Psychology (in press).

Patton, W. and King, R. The use of human judgement models in sales force selection decision, Joumal of Personal Selling and Sales Management (1992), pp. 1-14.

Paulhus, D., Sphere-specific measures of perceived control, Journal of Personality and Social Psychology (1983), pp. 1253-1265.

Paulhus, D. and Martin, C., Functional flexibility: a new conception of interpersonal flexibility, Journat of Personality and Social Psychology (1988), pp. 88-101.

Pervin, L., Goal Concepts in Personality and Social Psychology (Hillsdale, NJ: Lawrence Erlbaum Associates, 1989).

Prigogine, 1. and Strengers, E., Order Out of Chaos (New York, NY: Bantom Books, 1985).

Rapp, P., Jiminis Montano, M., Langs, R., Thomas, L. and Mess, A., Quantitative Characterization of Patient Therapist Communication (Working Paper, Medical College of Pennsylvania, PA, 1990).

Rotter, J. B., Generalized expectancies for internal yersus external control reinforcement, Psychological Monographs (1966; No, 609).

Shoner, G. and Kelso, J., Dynamic pattern generation in behavioral and neural systems, Science (1988), pp. 1513-1520. 
Snyder, M., The self-monitoring of expressive behavior, Journal of Personality and Social Psychology (1974), pp. 526-537.

Snyder, M. and DeBono, K., Appeals to image and claims about quality: understanding the psychology of advertising, Journal of Personality and Social Psychology (1985), pp. 586-597.

Snyder, M. and Gangestad, S., On the nature of self-monitoring, matters of assessment, matters of validity, Journal of Personality and Social Psychology (1986), pp. 125-139.

Snyder, M., Berscheid, E. and Matnychuck, A., Orienting towards personnel selection: differential reliance towards an appearance and personality, Journal of Personality and Social Psychology (1988), pp. 972-979.

Sperber, D. and Wilson, D., Precis of relevance: communication and cognition, Behavioral and Brain Sciences (1987), pp. 697-754.

Spiro, R. and Weitz, B., Adaptive selling: conceptualization, measurement and nomological validity, Journal of Marketing Research (1990), pp. 61-69.

\section{APPENDIX}

The correlations between the different tests were as follows:

Table A1. The correlations between the tests of the effective salespeople

\begin{tabular}{llllll}
\hline & Self-mon. & Intcont. & Openers & Rigidi. & Adapts \\
\hline Selfmon. & 1.0000 & & & & \\
Intcont. & $0.42^{*}$ & 1.000 & & & \\
Openers & $0.52^{* *}$ & $0.57^{* *}$ & 1.000 & \\
Rigidi. & $-0.39 *$ & -0.16 & -0.26 & & 1.000 \\
Adapts & $0.52^{* *}$ & $0.62^{* *}$ & $0.56^{* *}$ & $-0.51^{* *}$ & 0.13 \\
Perseff. & 0.01 & $0.44^{*}$ & 0.19 & 0.31 & \\
\hline
\end{tabular}

Table A2. The correlations between the tests of the ineffective salespeople

\begin{tabular}{llllll}
\hline & Self-mon. & Intcont. & Openers & Rigidi. & Adapts \\
\hline Selfmon. & 1.0000 & & & & \\
Intcont. & $0.55^{*}$ & 1.0000 & & & \\
Openers & $0.51^{*}$ & 0.42 & 1.0000 & 1.0000 & 1.0000 \\
Rigidi. & -0.29 & 0.04 & -0.30 & -0.07 & 0.08 \\
Adapts & 0.38 & 0.30 & 0.32 & 0.36 & 0.17 \\
Perseff. & 0.50 & 0.27 & & & \\
\hline
\end{tabular}

Table A3. The correlations between the tests of the total sample

\begin{tabular}{|c|c|c|c|c|c|}
\hline & Self-mon. & Intcont. & Openers & Rigidi. & Adapts \\
\hline Selfmon. & 1.0000 & & & & \\
\hline Intcont. & $0.50^{* *}$ & 1.0000 & & & \\
\hline Openers & $0.56 * *$ & $0.51 * *$ & 1.0000 & & \\
\hline Rigidi. & $-0.35^{*}$ & -0.10 & $-0.28^{*}$ & 1.0000 & \\
\hline Adapts & $0.50 * *$ & $0.48 * *$ & $0.47 * *$ & $-0.32 *$ & \\
\hline Perseff. & $0.28^{*}$ & $0.37 * *$ & 0.21 & $0.31^{*}$ & 0.13 \\
\hline
\end{tabular}

One-tailed: significance: *-0.01;**-0.001. 